\title{
Evaluating public opinion towards robots: a mixed-method approach
}

https://doi.org/10.1515/pjbr-2019-0023

Received June 27, 2019; accepted July 11, 2019

\begin{abstract}
The article presents the results of some research conducted in Italy on the perception of robots. The study was carried out as part of a project arranged by the School of Robotics (Scuola di Robotica) in 2017/2018 and involved around 700 Italian citizens belonging to different social groups. Data collection used mixed methods: surveys, focus groups, interviews, and participatory workshops. The results were compared with surveys conducted in Europe by the Eurobarometer.

Italy is an interesting context for this type of study for the density of robots, for the growth trends of robotics compared to other countries and for the relationships between industry and the labor market. The results of the research show that the attitudes and expectations of Italians towards robots are complex, multidimensional and contradictory: on the one hand, the interviewees positively value the growing presence of robots, on the other, they show fears about the spread of robotics in society. Robots, especially those designed to interact with humans, are part of a large system influenced by social, cultural and environmental factors in which actors move with different expectations and needs. The presence of a significant degree of differentiation between the responses of the different socio-demographic categories confirms the importance of investigating these issues, in order to reduce the distance that persists between researchers and scientists and the impact of technology on society. Furthermore, robotics is often narrated with myths and legends that have no correspondence in reality; since robots will interact more fully with humans, the human-robot interaction process and the bias integrated into the technology must be carefully studied to avoid the risks of confirmatory bias.
\end{abstract}

Keywords: artificial intelligence, assistive robots, attitude towards robots, robot, roboethics, social interaction, social factors in robotics, survey

\footnotetext{
*Corresponding Author: Stefania Operto: University of Genova, DISFOR, Department of Science of Education, Genova, 16100, Italy; E-mail: stefania.operto@unige.it
}

\section{Introduction}

In this article the author presents a study on human-robot interaction conducted in 2017/2018 in collaboration with the Italian non-profit organization Scuola di Robotica, carried out with a national project called 'Ogeima'.

The aim of the research was to detect people's opinions and attitudes towards robots and to observe directly behaviors and reactions towards humanoid robots. The research was conducted on a sample of Italian citizens with a mixed-method research approach; standard and nonstandard methods were used: surveys, focus groups, interviews, participatory workshops and mock-up studies robots $[1,2]$. The results of the research conducted in Italy were compared with research carried out at European level by Eurobarometer [3-5]. Unlike the Italian study, the Eurobarometer research uses only the survey method.

The Italian case seemed interesting for several reasons. Over time, Italy has established a significant position in the international robotics landscape; in 2018 Italy ranked seventh worldwide after China, Japan, the United States, Korea, Germany and Taiwan for the supply of industrial robots [6].

Between 2008 and 2018 the number of robots in Italian production plants increased by an average of $7.3 \%$ per year, but it is in the most recent period that domestic demand has registered the greatest increase. In 2018 the number of robots installed in factories increased by $11.5 \%$ compared to 2017. In the same year the production of robots grew by $28.7 \%$ compared to 2017 ; over $39 \%$ of robots were sold abroad [7].

Whereas Italy is the second European nation and the fourth in the world in terms of robot density, from the point of view of the labor market it is among the nations with the highest rate of youth unemployment [8]. The results, illustrated later on, show that it is precisely younger Italians who are most concerned about the impact of robotics on the labor market.

Service robotics is entering a new development phase and sustained global growth. Once the industrial segregation era was overcome, service robotics - of professional and personal applications - have been employed in grow- 
ing applications. According to the IFR's World Robotics Report 2018 [9], professional robots have already had a significant impact in areas such as agriculture, surgery and medical applications, logistics, and public relations. Furthermore, robots will play an even greater role in the maintenance, security and rescue fields.

In 2015-2017, personal and domestic robots were marketed in growing numbers, even though in a limited number of products: these are floor cleaning robots, domestic window cleaning, pool cleaning, robot-mowers, sports robots and robots for edutainment and telepresence. In addition, progress in the fields of Human-Robot Interaction and Physical-Human-Robot Interaction suggests that within a few years the market will be offering assistive robots with the ability to interact with the elderly, with patients, people in rehabilitation, children and even people with various disabilities.

Indeed, the request for social assistive robots in Europe derives both from the growth of the elderly population and from the confirmation that social robots can have a significant impact on the improvement of daily habits and lifestyles such as, among others, the management of diets, sports, medical treatments, communication between people, and the fruition of individual cultural needs $[10,11]$. Today, some smart and programmable objects (IoT, Internet of Things) of common use are available on the market such as Smart Irrigation Controllers, WIFI Lighting, Wireless Smart Vents, and Smart Thermostats.

During the last decade, the pervasiveness of these technologies and their growing importance in our daily lives have motivated researchers in Europe, in the USA and Japan to study the impact, perception and acceptance of robotics in our society. Initially limited to technicalspecialist fields, the analyses were subsequently extended to include psychology, sociology, ethics, philosophy and law. Many of these studies have also shown negative attitudes of fear and resistance towards robots [12, 13], revealing significant differences between different population categories [14].

The results of Italian research also show that attitudes and expectations towards robots are complex, multidimensional, and associated with a certain degree of contradiction and ambivalence. On one hand, respondents expressed a positive attitude about the beneficial effects of robots, but this perception is combined with fears about the growing importance of robotics in everyday life.

In designing the research conducted in Italy, the author took into account the fact that the public perception of robots is often influenced by collective images and constructs, full of symbolic meanings, deriving from literature, films and mythical stories. Around the theme of robotics, in particular the humanoid one, a frame $[15,16]$ has developed with sensationalistic contours; humanoid robotics, due to the analogies with the concept of humanity itself, favors the generation of a complex conceptual structure. The same word does not only indicate the machine but brings together very different domains: law, economy, work, quality of life, well-being of the community, ethics, philosophy and religion [17].

The frame around robotics is expressed by feeding opposing fronts synthesized in two orientations: on the one hand, enthusiasm and willingness to spread robotics in society and, on the other, opposition and adversity often associated with the support of policies of limitation. These two opposing attitudes, strengthened by the widespread use of negation to support each other's positions, denying on a case-by-case basis either the advantages or the risks of the spread of robots reinforce the frame itself [18], contributing at the same time to spreading false information.

This mechanism is particularly relevant in Europe, where the public perception of robots is influenced by misconceptions about robotics and by a generalized fear about the applications of science and technology [19]. Robotics has not yet dropped its fiction frame of reference so often robotic researchers and producers are unable to communicate effectively with the public. The oftensensational media coverage also encourages false illusions about robots' effective performance.

Finally, improving the understanding of public opinion about robots is key for researchers and research institutions, for manufacturing industries and for end users [11]. In view of the fact that, among European citizens, the personal experience of robots is still rather limited [3-5], effective research must take into account a complex of factors, including the presence of stereotypes, myths, illusions, real needs and fears concerning robots.

\section{Studies about the perception of robots in Europe}

Research funded by the European Commission (EC) has analyzed the attitudes of European citizens towards robots with three quantitative surveys carried out in 2012 [3], 2014 [4] and 2017 [5] by Eurobarometer, the research program which has been analyzing public opinion trends since 1973. These surveys examine many aspects of this issue: the impact of digital technologies on society, the economy and quality of life, citizen's self-reported level of skills in making use of digital technologies at work, for learning, and in using online public services, the use of robots 
at home or at work, attitudes towards robots and artificial intelligence, including their impact on jobs, and the level of comfort citizens have with robots performing a range of tasks, the use of online healthcare, citizens' desire for online access to their own health and well-being data, and their willingness to share this with others.

In this paper, the author's choice to use Eurobarometer's data is due to several reasons. Firstly, the research presented here, carried out in Italy by the Scuola di Robotica, refers to a sample of Italian citizens; it therefore seemed more pertinent to include and compare the results with those collected in Europe. Secondly, the Eurobarometer surveys, which are the official data collection and studies of the EU, guarantee an adequate level of representativeness and quality of the data. Finally, Eurobarometer represents one of the few sources that examines a large number of European countries simultaneously.

Besides the Eurobarometer survey, in this paper we quote two other surveys on the subject. However, these are limited to specific geographical areas or to specific contexts of application of robotics, mostly in the field of assistance to elderly people and people with disabilities or cognitive difficulties. Research that investigates the attitudes towards robots in the broadest sense, and that examine all socio-demographic categories in order to identify the existence of significant causal relationships for large social groups, seems to be less common.

For the purposes of this paper, it is useful to recall some of the results from Eurobarometer 2017 survey [5]: a) more than six people in ten have a positive view of robots and artificial intelligence (61\%);

b) more than eight in ten respondents agree robots are necessary as they can do jobs that are too hard or too dangerous for people (84\%), and 68\% agree that robots and artificial intelligence are a good thing for society because they help people do their jobs or carry out daily tasks at home; c) almost nine in ten respondents agree that robots and artificial intelligence are technologies that require careful management (88\%);

d) almost three quarters agree that due to the use of robots and artificial intelligence, more jobs will disappear than new jobs being created (74\%), and almost as many agree that robots and artificial intelligence steal people's jobs (72\%);

e) more than four in ten respondents who are currently working think their current job could at least partly be done by a robot or artificial intelligence (44\%);

f) although the majority of respondents have not used a robot at home or at work (85\%), one third of them say they would be comfortable having a robot assist them at work
(35\%). More than one third are also comfortable with receiving goods delivered by a drone or a robot (35\%);

g) more than one quarter of respondents are comfortable with having a robot to provide them with services and companionship when infirm or elderly $(26 \%)$ or with having a medical operation performed on them by a robot (26\%); h) less than a quarter of respondents (22\%) would be comfortable being driven in a driverless car in traffic.

It is interesting to note that the opinion about robots/AI depended strongly on the exposure to information/knowledge. Eurobarometer respondents who had heard, read or saw something about artificial intelligence in the 12 months before the survey was carried out were more likely to have a positive view of artificial intelligence and robots ( $75 \%$ vs. $49 \%$ who had not).

Between 2016 and 2017, some other surveys were carried out which, unlike the Eurobarometer survey, focused on specific aspects of public perceptions about robots, in particular the introduction of robots in humanreplacement workplaces. In 2016, the British Science Association (BSA) conducted a survey to understand how the public thought robotics and artificial intelligence could affect society and culture. It was an online survey, which had over 2,000 responses, it was conducted by YouGov on behalf of the British Science Association. The research results were discussed during British Science Week 2016 [20]. The survey found that: 60 per cent of respondents thought that the use of robots or programs equipped with artificial intelligence (AI) would lead to fewer jobs within ten years; 36 per cent believed that the development of AI posed a threat to the long-term survival of humanity [21].

In the USA, in 2017 the Pew Research Center, a nonpartisan survey institute monitoring issues, attitudes and trends, conducted a survey with the aim of evaluating “Americans' expectations and attitudes toward a world in which advanced robots and computer applications are competitive with human workers on a widespread scale" [22]. The survey was set specifically for a scenario in which robots and computers have moved beyond performing repeated or routine tasks and are capable of performing most of the jobs that are currently done by humans. In this case, the first important answer was that although some of the scenarios presented in the survey were futuristic, most of respondents consider this scenario to be plausible. As a whole, the survey found that many Americans foresee significant impacts from various automation technologies in the course of their lifetimes from the widespread adoption of autonomous vehicles to the replacement of entire job categories with robot workers. Although they expect certain positive outcomes from these developments, their attitudes more frequently reflect 
worry and concern over the implications of these technologies for society as a whole.

In addition to the surveys mentioned above, numerous research programs have been carried out on humanmachine interaction and on the effects on everyday life of the use of robots. These studies, often specialized and sectoral, examined specific aspects: assistance to people with physical or cognitive disabilities; the use of robots with specific categories of recipients, typically the elderly [23, 24]; medicine; training, education and teaching; logistics and transport; home automation [25].

The results of these studies show that the acceptability depends on both intrinsic factors like motivation, attitudes, knowledge, and experience and extrinsic factors related to the social, cultural and relational context. The design of assistive robots has to comply with the ecology of people, support their values, and adapt to all the members of the system who will interact with the robots [26]. Furthermore, some studies confirm that all the stakeholders involved in the introduction of robot in their milieu, have to understand the benefits of a robot in order for it to be accepted [27]. Other research [28] shows that the acceptance of robots depends on subjective users' perceptions of what robots are, how they work, and what they can and cannot do.

Robots, especially those designed to interact with human in daily life, are part of a large system influenced by social, cultural and environmental factors in which participants and stakeholders move with different needs and expectations [17, 29].

Other studies centered around the development of Human-Robot Interaction as a way of making robots more friendly and usable by everyone [30]. Understanding the attitudes of the recipients of these technologies, their degree of acceptance and trust can promote the well-being expected from this new stage of human development.

The research on the public perception of robots carried out in Italy by Scuola di Robotica, presented in the following sections, confirms the majority of the results of the Eurobarometer survey, and also how public opinion about robots and the level of their acceptance depend on the cultural and social milieu in which they are to be integrated. The narrative frame by information and media agencies contributes to shape public opinion and to stabilize two opposing fronts: one positively oriented towards technology, the other tenaciously opposing it.

\section{The Italian case study}

As mentioned in the introduction, Italy is an interesting case study to collect data on these issues. From the point of view of general knowledge of and familiarity with robots, in Italian culture there is interest in machines that started from admiration for the figure of Leonardo da Vinci [31] and continued in the process of industrialization and with the birth of the Polytechnics.

In Italy in the nineteen-fifties, several automation companies were born or upgraded, including Olivetti who designed one of the first robots: SIGMA [32]. In Europe, the first robotic welding lines were installed in 1972 in Italy (Fiat) and in the same year in Japan (Nissan) [33].

Today, Italy is the second European integrator after Germany and among the top ten for acquisitions and density of robots per population. In 2016, Italy was the third largest exporter of robotics [34]. From the point of view of the presence of robotic research centers, Italy has several excellent, public and private robotics research centers.

As for the need for and interest in robots, especially service robots, attention is also due to the fact that from a demographic point of view Italy is, together with Japan, one of the countries with the oldest population in the world: in 2017, there were over 13.5 million Italians who were over 65 years old and they accounted for $22.3 \%$ of the total population [35].

It is understandable that from both a social and a purely commercial point of view, there is interest in the adoption of robots that can support the quality of life of an increasingly elderly population. In Italy, as in Japan, although with less planning decision, studies and manufactures are focused on service robotics, especially robots for safety and control of the environment, and also to assist the elderly.

From the point of view of the Italian industrial profile, in this case it can also be observed that the interest in robotics and automation is high. In fact, Italy's manufacturing and industrial structure is mainly composed of small and medium-sized enterprises (SMEs) that try to compete with the market giants thanks to some products of excellence; at the same time, they have to progressively lower their production costs. Given high labor costs in comparison with Asian nations, in Italy the replacement of human workers with robots has been a constant trend since the 1980s. Today, 25 percent of Italian manufacturing companies use robotics in the manufacturing process [34].

Moreover, from the point of view of training and the need to innovate schools and education, in 2017 the Italian Ministry of Education launched an ambitious project 
to reform the content of school curricula by including educational robotics among the educational technologies and innovative devices to support STEM subjects [36].

In conclusion, Italy, with its contradictions oscillating between de-industrialized areas and areas and centers of innovation and excellence in robotics, is an interesting nation in which to study the public perception of robots.

\section{Attitudes towards robots in Italy}

\subsection{Research methods}

The analyses conducted by the author, the project's scientific director, refer to data collected in the two-year period 2017/2018 in the research project 'Ogeima Story: human languages, machines, representations' [37].

Ogeima is the name of a move in the game of Go, an ancient game of Chinese origin; the game of Go has long been viewed as the most challenging of classic games for artificial intelligence owing to its enormous search space and the difficulty of evaluating board positions and moves. In 2016, an artificial intelligence system beat the then world champion for the first time; this was the first time that a computer program had defeated a human professional player in the full-sized game of Go [38]; hence the name of the project.

The research design included a mixed-method approach: surveys, focus groups, interviews, and participatory workshops implemented with robot mock-up studies were carried out. The different research phases were carried out with quantitative, qualitative and nonstandardized stimuli: the quantitative phase was carried out through a questionnaire with closed questions administered both face to face and online (505 participants); the qualitative phase used focus groups (8 focus groups), interviews (20 interviews) and participatory workshops and robot mock-up studies that allowed us to observe the interaction in presence between humans and humanoid robots like Nao and Pepper. It appeared useful to integrate the survey data with the results of three simulations carried out in the framework of the participatory workshops:

a) the design: the participants were encouraged to imagine building an ideal robot from the point of view of the functions and what they wanted it to do and not do (stimulus proposed in the robot mock-up study);

b) the relationship: the participants produced a communicative context between a human being and a robot, outlining all aspects: dialogical, spatial, relational (stimulus proposed both in the survey and in participatory workshops);

c) the expectations: in this phase the reflection focused on what participants expect from robots in terms of advantages and disadvantages (stimulus proposed in both the survey and the participatory workshops).

The study also scheduled a question to respondents about the meaning of the word robot: what the study wanted to analyze was not the knowledge people have of robotics, but the reaction that they express to stimuli related to robotics, in other words what people think and translate into opinions and attitudes in relation to the set of knowledge they believe they have on the subject. This is to confirm that acceptance of robots is dependent on subjective users' perceptions of what robots are, how they work, and what they can and cannot do $[28,39]$.

In this perspective, attitudes towards robotics are understood not only as the result of learning process mediated by culture and education, but also as a result mediated by experiences and the social context.

The themes were proposed with a funnel-shaped structure with the aim of encouraging a progressive reflection. Starting from the issue of the effect of service robots on the quality of life, the author proposed to the participants more specific themes: the perceived impact of robotics on safety, on work, on scheduling the daily life, going so far as to reflect on philosophical dimensions such as the possible consequences of the spread of robots on the freedom of humans.

Considering the specificity of the theme, the choice was oriented towards a purposive sampling with nonproportional quota to assure that smaller groups were adequately represented in the sample. A total of more than 700 people distributed throughout Italy participated in the various research phases.

As validation elements, some requests for verification on the relationship between respondents and technology were also included in the questionnaire. The analysis of the research material was carried out using both statistical techniques and an approach based on discourse analysis. This considers language a human activity that produces meanings and social practice [40] and allowed analyzers to expand the variables analysis - oriented towards standardization - to contextual elements inserted on multiple levels. The author did not limit herself to analyze the questions but to understand - within the limits of the partiality and contingency of the research - the communication context, in which the answers were expressed, observing the interactions between the respondents and the humanoid robots Pepper and Nao. From these complementary data some interesting - and in a few cases unexpected - new el- 
ements contributing to forming people's attitudes towards robotics came out.

\subsection{Survey results: acceptance, expectations, perplexity, and fears}

Public understanding of science and technology is often dominated by the debate on risks [19]. However, both the EC $8^{\text {th }}$ Framework Program and the 2030 UN Agenda indicate science and technology as an incredible tool to solving many of today's issues [41].

Regrettably, Italy ranks $25^{\text {th }}$ out of the 28 Member States in the Digital Economy and Society Index (DESI) [42]; as in previous years, the main challenge is still a low level of digital skills. In particular, Italy has failed to make progress on Internet use and remains second to last: a contradictory framework of hopes and delusions about technology.

According to the Eurobarometer survey (2017) [5], three quarters $(75 \%)$ of respondents think the most recent digital technologies have a positive impact on the economy, while $67 \%$ think these technologies have a positive impact on their quality of life and $64 \%$ think these technologies have a positive impact on society. The results of this Italian survey appear in line with the European data: the majority of the participants answered that the progressive diffusion of robots could improve people's quality of life. However, as for the degree of agreement, this is not total: $59.6 \%$ of respondents say they Tend to Agree, thus expressing some perplexity, and only $27.8 \%$ Totally Agree. Moreover, the percentage of those who declare that they Totally Disagree (12.6\%) is not negligible (Table 1).

Table 1: The diffusion of robots in society will improve people's quality of life.

\begin{tabular}{lr}
\hline & $\%$ \\
\hline Totally agree & 27.8 \\
Tend to agree & 59.6 \\
Tend to disagree & 11.1 \\
Totally disagree & 1.5 \\
\hline Total & 100 \\
\hline
\end{tabular}

Source: Scuola di Robotica.

Note: $N$ (505).

The data collected during the qualitative phases - participatory workshops and focus groups - highlighted some elements of perplexity and fear. Below the conceptual domains with assembled data: (a) Replacement. Fear of replacement: humans might be replaced in all activities by robots. 'I don't want a robot as a teacher. At most it might be able to correct students' homework, but I don't like the idea that a robot replaces the teacher in the interaction with the students' (participant 367B).

(b) Regulation \& Control. Respondents call for the need to control and regulate very carefully the deployment and activities delegated to robots: 'Who decides what's right or wrong for a robot to do? And if it is wrong, who is responsible for it?'(participant 147B); 'I am aware of the benefits of robots in many areas, but I don't want to delegate the care of my loved ones to a robot' (participant 260B).

(c) Privacy. The diffusion of robots poses issues of data security and also of freedom: 'There will be no privacy anymore. Imagining that one person alone could dominate the whole world terrifies me' (participant 188A).

(d) Human relations. The development of advanced technology may disrupt 'communication and relationships between human beings' (participant 123A); 'Already today, many people close to me like to communicate more with a digital device than with a human looking them in the eye' (participant 200B).

(e) Technology Addiction. The issue of technology addiction is already known, in particular with reference to the Internet addiction disorder (IAD). Many respondents referred to it: 'I have become addicted to the Internet and the network. I must be constantly wired up to socials, emails. I cannot imagine how I will end when connected to a robot' (participant 345A); 'I am too dependent on digital technology, and I waste too much time that I could spend on experiences in the real world' (participant, 268A).

(f) Delegation. Several respondents expressed their fear that the process of delegating human functions to robots could cause negative consequences, especially in terms of job losses - an alarming issue [43, 44, 45]: 'If robots can do the things human beings do, even better and faster, what will remain to be done by humans?' (participant 309B).

g) Critical Thinking. Some fear that human cognitive and learning processes will change: 'The speed of learning is so accelerated, jeopardizing those moments of reflection necessary to foster our independent thinking' (participant 466B); Knowledge is losing its role, and the ability to select the correct information is disappearing' (participant 101B).

(h) Body. Fears emerge that advances in medical robotics and medical applications may partially disrupt the perception of the dimension of human body: 'Humans and robots must be distinguishable from each other: if one day all our body parts could be replaced, how will we distinguish a human from a robot?' (participant 133A). 
Amongst the respondents, women and people in the middle age groups (45-54 and 55-64) are those who have the greatest confidence that robotics could be improving humans' quality of life. Anticipating the results shown below, young people, in particular young males, appear more concerned about some negative impacts of robots on job losses, young females about possible reduction of their personal freedom.

The survey investigated in detail some important dimensions related to well-being; one of these deals with the possible time saving resulting from the progressive use of robots. Evaluating the perception of well-being (individual and of a community), time is a very important indicator having various dimensions: work, education, health, affection, care for oneself and one's family. All these dimensions are found in the 17 Sustainable Development Goals (SDGs) that make up the "Agenda 2030" [41]; many references to people's well-being and to an equitable distribution of the benefits of development are present as indispensable components. The possibility of achieving these objectives also calls for the availability of time, which appears to be a resource distributed in a heterogeneous way due to the disparities in the distribution of wealth in the world. In post-modern societies, time, since it involves fundamental aspects such as the life cycle, affectivity, family, caring for oneself and others, sociality and relationships, represents an immaterial resource that people consider increasingly limited and that puts it at the top of the ranking of important aspects for well-being.

Will the spread of robotics save people time and energy? On this subject, Italians seem to agree: more than half $(52.3 \%)$ consider very positively (Totally agree) the possibility that the diffusion of robots could free some time for humans, and $40.3 \%$ Tend to agree. Overall, this includes almost the entire sample (92.6\%) (Table 2).

Table 2: The diffusion of robots will save people time and energy.

\begin{tabular}{lr}
\hline & $\%$ \\
\hline Totally agree & 52.3 \\
Tend to agree & 40.3 \\
Tend to disagree & 5.7 \\
Totally disagree & 1.7 \\
\hline Total & 100 \\
\hline
\end{tabular}

Source: Scuola di Robotica.

Note: $N$ (505).

Another important issue often raised when talking about digital technologies is the chance that robots could improve a community's security, both in terms of control
Table 3: The spread of robots will make people feel safer.

\begin{tabular}{lr}
\hline & $\%$ \\
\hline Totally agree & 16.2 \\
Tend to agree & 45.9 \\
Tend to disagree & 32.6 \\
Totally disagree & 5.3 \\
\hline Total & 100 \\
\hline
\end{tabular}

Source: Scuola di Robotica.

Note: $N$ (505).

of urban areas and human settlements, and in terms of individual safety. Security is described by some objective indicators, for example the number of crimes and misdemeanors occurring in an area in a certain time span, along with individual attitudes and perceptions - the perception that one could be a victim of aggression, of individual fear of walking alone at night in certain zones of the city

Will the diffusion of robotics increase people's security? To this question (Table 3) respondents answered positively, even if without full consensus: $16.2 \%$ of the respondents declared they Totally agree with this statement and 45.9\% Tend to agree. Overall, more than half of respondents (62.1\%) believe that robotics can have positive effects on security. It is important to weigh the quantitative data against the results of the qualitative phases. From the narrative phase of the survey, the author collected the respondents' perception that robots employed in security tasks could also be a source of danger, if not controlled by reliable agencies.

In fact, technological development could be a cause of concern. This emerges from an apparently opposite dimension to the previous one: the fear that the spread of robots could create problems for people's security. In this case (Table 4) the majority of respondents declare that they do not agree with this statement $(69.2 \%)$, but the proportion of those who express perplexity on this issue which amounts to little less than a third of the total (30.9\%), appears significant.

Safety is also linked to individual security. During the participatory workshops, many participants expressed the fear that robots could be used voluntarily or unintentionally to harm human beings, highlighting the need to define regulatory policies for designers, builders, and scientists.

Another central theme that is creating a global debate is the implication of robotics in the workplace. As confirmed recently by various research [43-45] it is indubitable that jobs will change profoundly in the future due to ICT, cloud and robotics technology. The weight and role of some professions will be reduced, and others will dis- 
Table 4: The spread of robots in society will create safety problems.

\begin{tabular}{lr}
\hline & $\%$ \\
\hline Totally agree & 5.2 \\
Tend to agree & 25.7 \\
Tend to disagree & 55.8 \\
Totally disagree & 13.3 \\
\hline Total & 100 \\
\hline
\end{tabular}

Source: Scuola di Robotica.

Note: $N$ (505).

appear, but what is most likely is precisely the transformation of production and work processes in terms of time and space. This survey's respondents confirmed the results of the quoted studies on this subject, because they expressed a medium-high level of concern: more than half (64.2\%) said they shared the fears regarding the loss of jobs caused by the spread of robots (Table 5 ).

Table 5: The spread of robots will lead to human substitution at work.

\begin{tabular}{lr}
\hline & $\%$ \\
\hline Totally agree & 30.8 \\
Tend to agree & 33.4 \\
Tend to disagree & 23.4 \\
Totally disagree & 12.4 \\
\hline Total & 100 \\
\hline
\end{tabular}

Source: Scuola di Robotica.

Note: $N$ (505).

The last dimension for questions was about freedom. The notion of freedom involves many aspects of human life: relationships, corporeity and all the dimensions that contribute to characterizing the human condition.

Could robots be used to reduce and limit human freedom? (Table 6). The majority of respondents declared that they disagree with this statement (64.2\% Totally disagree plus Tend to disagree), but a considerable quota (35.8\% Totally agree plus Tend to agree) - expressed concerns about the issue. This quota of positive answers to the question is interesting, especially if related to the benefits expected from the diffusion of robots.

The issue of freedom seems strongly correlated with those about privacy, about concerns on substitution and the request that the use of robots be thoroughly regulated and controlled.

The phases of qualitative research and the participatory workshops allowed us to point out that only a limited
Table 6: Robots could be used to reduce and limit human's freedom.

\begin{tabular}{lr}
\hline & $\%$ \\
\hline Totally agree & 11.5 \\
Tend to agree & 24.3 \\
Tend to disagree & 41.7 \\
Totally disagree & 22.5 \\
\hline Total & 100 \\
\hline
\end{tabular}

Source: Scuola di Robotica.

Note: $N$ (505).

number of people who participated in the study stated that they had had experience with robots.

\subsection{Correlations and indexes}

For the most relevant dimensions, further analyses have been carried out. Firstly, a standard index has been calculated; the index varies from 0 to 100. Zero - 0 - represents the minimum level of acceptance of the issue, 100 the maximum level. Looking at the evolution of the indexes about confidence towards robots, disaggregated by groups, some relevant trends can be observed (Tables 7 and 8). The dimension that scores the highest level of positive answers is about robots improving human's time saving ( $(=81)$, underlined especially by women ( $\mathrm{I}=82$ ) compared to men $(\mathrm{I}=80)$. Women suffer more than men, and more in Italy than in other countries, from an unbalanced distribution of family workloads and have problems in reconciling personal time and work times. The second highest level of the confidence index pertains to the possibility that robots will be fostering human's well-being $(\mathrm{I}=71)$ : The third highest level concerns benefits for human safety $(I=58)$. Confidence in robots' positive effect on human well-being and security is more widely supported by the elderly, and this is due to their feebleness as compared to others.

Of negative dimensions, a first concern is the possible loss of jobs ( $I=61)$ which appears to be more frequent among young people, especially young men. The second concern is the fear of losing freedom $(\mathrm{I}=42)$ and the third about security issues caused by robots to humans $(I=41)$. Young people are more likely to fear the negative effect of robots on human freedom, while issues related to security are uniformly distributed across all groups (Table 8 ).

The presence of differentiated opinions by social groups is confirmed by the correlation analysis: as age decreases, there is growing concern about possible job losses caused by robot replacement (Pearson's $r=-.317$ ) and about risks for human freedom (Pearson's $r=-.196)$ (Table 9). 
Table 7: Spreading of robots in the society and welfare, time saving and safety. Trust index*

\begin{tabular}{lccc}
\hline & $\begin{array}{c}\text { Quality of life and its } \\
\text { improvement }\end{array}$ & Time saving machines & Increased security \\
\hline Males & $\bar{I}$ & $\bar{I}$ & $\bar{I}$ \\
Females & 71 & 80 & 58 \\
& 72 & 82 & 57 \\
$<25$ years & & 82 & 54 \\
$25-34$ years & 66 & 83 & 53 \\
$35-44$ years & 69 & 81 & 57 \\
$45-54$ years & 71 & 84 & 62 \\
$55-64$ years & 80 & 81 & 64 \\
65 years and over & 78 & 70 & 68 \\
& 78 & & 58 \\
\hline Total & 71 & 81 & \\
\hline
\end{tabular}

Source: Scuola di Robotica.

Note: $N$ (505).

${ }^{\star}$ Normalized value from 1 to 100 .

Table 8: The spread of robots in society and problems of safety, loss of jobs, restriction of freedom. Trust indexes.

\begin{tabular}{lccc}
\hline & $\begin{array}{c}\text { Quality of life and its } \\
\text { improvement }\end{array}$ & Time saving machines & Increased security \\
\hline Males & $\bar{I}$ & $\bar{I}$ & $\bar{I}$ \\
Females & 42 & 65 & 41 \\
& 41 & 58 & 42 \\
$<25$ years & & 77 & 46 \\
$25-34$ years & 42 & 69 & 47 \\
$35-44$ years & 42 & 57 & 40 \\
$45-54$ years & 38 & 48 & 31 \\
$55-64$ years & 37 & 45 & 38 \\
65 years and over & 42 & 59 & 44 \\
& 43 & & 42 \\
\hline Total & 41 & 61 & \\
\hline
\end{tabular}

Source: Scuola di Robotica.

Note: $N$ (505).

*Normalized index from 0 to 100 .

Table 9: Correlation (Pearson's r) between age and indicators.

\begin{tabular}{lcccc}
\hline & $\begin{array}{c}\text { Quality of life and } \\
\text { its improvement }\end{array}$ & $\begin{array}{c}\text { Timesaving } \\
\text { machines }\end{array}$ & Increased security & $\begin{array}{c}\text { Freedom } \\
\text { limitation }\end{array}$ \\
\hline Age & & & & -.196 \\
Correlation & .176 & .127 & -.317 & 427 \\
N & 441 & 423 & 440 & 4 \\
\hline
\end{tabular}

It is interesting to analyze the correlation between the dimensions: confidence in robots as a factor for improving human well-being is positively correlated to time savings (Pearson's $r=4.50$ ), and expectations that robots could increase people's security (Pearson's $r=.386$ ). Therefore, time and security appear two key dimensions affecting quality of life. Vice versa well-being appears negatively correlated with the fear that robots create problems of se- 
Table 10: Correlation (Pearson's r) between indicators.

\begin{tabular}{|c|c|c|c|c|c|c|}
\hline & $\begin{array}{r}\text { Quality of life } \\
\text { and its } \\
\text { improvement }\end{array}$ & $\begin{array}{r}\text { Timesaving } \\
\text { machines }\end{array}$ & $\begin{array}{r}\text { Increased } \\
\text { security }\end{array}$ & $\begin{array}{r}\text { Security } \\
\text { issues }\end{array}$ & $\begin{array}{r}\text { Freedom } \\
\text { limitation }\end{array}$ & $\begin{array}{r}\text { Human } \\
\text { substitution } \\
\text { at work } \\
\end{array}$ \\
\hline Quality of life & 1,000 & .450 & .386 & -.149 & -.314 & -.279 \\
\hline and well-being & N (441) & $N(457)$ & N (435) & N (441) & N (441) & $N(452)$ \\
\hline \multirow{2}{*}{ Time saving } & .450 & 1,000 & .374 & -.201 & -.253 & -.148 \\
\hline & $N(457)$ & $N(461)$ & $N(436)$ & N (441) & $N(442)$ & N (454) \\
\hline Increased & .386 & .374 & 1,000 & -.166 & -.192 & -.174 \\
\hline security & $N(435)$ & $N(436)$ & N (438) & N (426) & $N(422)$ & N (433) \\
\hline Concern about & -.149 & -.201 & -.166 & 1,000 & .354 & .200 \\
\hline security issues & $N(441)$ & N (441) & $N(426)$ & N (444) & N (429) & N (437) \\
\hline Freedom & -.314 & -.253 & -.192 & .354 & 1,000 & .387 \\
\hline reduction & N (441) & $N(442)$ & $N(422)$ & N (429) & N (444) & $N(438)$ \\
\hline \multirow{2}{*}{$\begin{array}{l}\text { Human } \\
\text { replacement and } \\
\text { job losses }\end{array}$} & -.279 & -.148 & -.174 & .200 & .387 & 1,000 \\
\hline & $N(452)$ & N (454) & N (433) & N (437) & N (438) & $N(458)$ \\
\hline
\end{tabular}

curity (Pearson's $r=-.149$ ), unemployment (Pearson's $r=-.279$ ) or limit individual freedom (Pearson's $r=-.314$ ) (Table 10).

The correlation between concern for job losses and for reduction of freedom is significant (Pearson's $r=.387$ ), as is the correlation between security issues and reduction of freedom (Pearson's $r=.354$. Thus, individual freedom appears to be a construct associated with jobs and security, both potentially threatened, in the opinion of research participants, by the progressive diffusion of robots. The observations conducted in the participatory workshops allowed us to suppose that these concerns are also related to the type of robot. In the case of assistive robots supporting children, elderly and sick persons, concerns are related to the process of delegation of human functions by non-autonomous people (sick or disabled parents and relatives) to robots. As for robots designed to replace human beings in the workplace, respondents opposed them more forcefully, with the only exception of activities dangerous for humans.

\section{Conclusions: The usefulness of mixed methods}

The results show different attitudes towards robots in social groups; women generally show higher levels of confidence in the possibility that robots can save some of their time currently occupied by repetitive activities: time is a dimension related to well-being. In Italy, as mentioned, the division of roles between men and women within households is still traditionally unbalanced by placing a burden on the female component. Robots could rebalance gender relations with appropriate education programs. An emblematic example: the washing machine was found to be for the whole sample interviewed the most difficult device to use, with a higher concentration of responses among women (65\%) compared to men (45\%).

At the same time, women, especially young women, fear more than men that robots can limit humans' freedom and are more concerned with the impact of robots in areas such as education and assistance.

The issue of job losses emerges with greater emphasis among young people, especially young males who appear more concerned with possible replacement; the maintenance of human job places is considered by them an essential condition also to limit the possible negative effects caused by robots on individual freedom. Individual freedom thus appears to be a construct associated with work and security, both of which are potentially threatened, especially in the opinion of young people, by the progressive diffusion of robots.

The elderly are more confident that robots can produce positive effects on well-being and security, a concept linked to quality of life; the expectations of this social group appear high considering the Italian demographic 
trend, characterized by the progressive aging of the population, low birth rate, and nuclearization of the family.

The respondents, expressing opposing opinions among the social groups interviewed, bring out the ethical and regulatory issues of the phenomenon; many participants, during participatory workshops, expressed their concern that robots could be used voluntarily or unintentionally to harm human beings, highlighting the need to define regulatory policies for designers, producers, scientists, and end users.

Each conclusion leaves a margin of provisional, opening to new research. The research results show that gender and age - and the social roles deriving from the combination of these variables in life course - are two important variables for determining attitudes towards robots. The results confirm that public perception of service and personal robots - and the resulting level of acceptance - involves a wide system of human relationships, cultural and social factors, and several stakeholders with different expectations and needs.

This research is limited to the Italian case only; therefore it is situated, partial and inscribed in a specific context. However, the adoption of the mixed-method approach proved particularly effective because of the possibility of integrating and implementing the different methods in order to answer research questions.

Acknowledgements: The author thanks the School of Robotics (Scuola di Robotica) for support during the research. The University of Genoa supported the research project, assessed it as interesting and implementable for the $\mathrm{PhD}$.

\section{References}

[1] J.W. Creswell, V.L. Plano Clark, Designing and conducting mixed methods research, 2nd ed., Thousand Oaks, CA: Sage, 2011

[2] J.W. Creswell, Research design: Qualitative, quantitative, and mixed methods approaches, 3rd ed., Thousand Oaks, CA: Sage, 2009

[3] European Commission, Directorate General for Communication, Public attitudes towards robots, Special Eurobarometer, 382, Brussels, 2012 http://ec.europa.eu/commfrontoffice/ publicopinion/archives/ebs/ebs_382_en.pdf

[4] European Commission, Directorate General for Communications General for Communications Networks, Content and Technology, Autonomous systems, Special Eurobarometer, 427, Brussel, 2015 http://ec.europa.eu/commfrontoffice/ publicopinion/archives/ebs/ebs_427_en.pdf

[5] European Commission, Directorate General for Communications General for Communications Networks, Content and Technology, Attitudes towards the impact of digitisation and automation on daily life, Special Eurobarometer 460, Brussels, 2017 https://ec.europa.eu/jrc/communities/sites/ jrccties/files/ebs_460_en.pdf

[6] International Federation of Robotics, World Robotics Outlook 2019 https://ifr.org/downloads/press2018/IFR_World_ Robotics_Outlook_2019_-_Chicago.pdf

[7] Robot: il mercato italiano cresce ancora a doppia cifra https://www.innovationpost.it/2019/05/17/robot-il-mercatoitaliano-cresce-ancora-a-doppia-cifra/

[8] R. Campa, Workers and Automata. A sociological analysis of the Italian case, The Journal of Evolution and Technology, 2014, 24(1), 70-85

[9] International Federation of Robotics, World Robotics Report 2017, Executive Summary World Robotics 2017 Service Robots, VDMA Robotics + Automation, Frankfurt am Main, Germany, https://ifr.org/free-downloads/

[10] M. J. Mataric, B. Scassellati, Socially assistive robotics, In: B. Siciliano, O. Khatib (Eds.), Springer Handbook of Robotics, 2nd Edition, 2016

[11] R. Kachouie et al., Socially assistive robots in elderly care: A mixed-method systematic literature review, International Journal of Human-Computer Interaction, 2014, 30(5), 369-393

[12] D. Loffredo, A. Tavakkoli, What are European Union public attitudes towards robots? Systemics, Cybernetics and Informatics, 2016, 14(1), http://www.iiisci.org/journal/CV \protect\T1\ textdollar/sci/pdfs/IP009LL16.pdf

[13] T. Nomura, T. Suzuki, T. Kanda, K. Kato, Measurement of negative attitudes towards robots, Interaction Studies, 2006, 7(3), 437-454, http://psycnet.apa.org/doi/10.1075/is.7.3.14nom

[14] P. Salvini, C. Laschi, C. P. Dario, Design for acceptability: improving robots' coexistence in human society, International Journal of Social Robotics,2010, 2(4), 451-460

[15] E. Goffman, Frame analysis: An essay on the organization of experience, Cambridge, MA, US: Harvard University Press, 1974

[16] G. Lakoff G., Don't think of an elephant! Know your values and frame the debate, Chelsea Green Publishing Co, 2004

[17] R. Campa, The rise of social robots: A review of recent literature, The Journal of Evolution and Technology, 2016, 26(1), 106-113

[18] G. Lakoff, M. Johnsen, Metaphors we live by, London: The University of Chicago press, 2003

[19] U. Felt, Taking European Knowledge Society Seriously, MURS, Paris, 2009

[20] British Science Association, https://www.britishscienceassociation.org/news/rise-ofartificial-intelligence-is-a-threat-to-humanity, 2016

[21] YouGov, https://today.yougov.com/topics/technology/articlesreports/2016/07/25/robots-jobs-inequality

[22] A. Smith, M. Anderson, PEW Research Center, Automation in Everyday Life, October, 2017

[23] J. M. Beer et al., The domesticated robot: Design guidelines for assisting older adults to age in place, In: Proceedings of the 7th Annual ACM/IEEE International Conference on Human-Robot Interaction (HRI'12), 2012, 335-342, DOI: http://dx.doi.org/10. $1145 / 2157689.2157806$

[24] M. F. Damholdt et al., Attitudinal change in elderly citizens toward social robots: The role of personality traits and beliefs about robot functionality, Frontiers in Psychology, 2015, 6, 1701

[25] G. Herrmann, M. J. Pearson, A. Lenz et al. (Eds.), Social Robotics: 5th International Conference, ICSR 2013, Bristol, UK, 
October 27-29, 2013, Proceedings, Lecture Notes in Computer Science, vol. 8239, Springer Verlag, Berlin-Heidelbergn DOI: 10.1007/978-3-319-02675-6

[26] J. Forlizzi, C. DiSalvo, F. Gemperle, Assistive robotics and an ecology of elders living independently in their homes, HumanComputer Interaction, 2004, 19(1), 25-59, DOI: https://doi.org/ 10.1207/s15327051hci1901\&2_3

[27] R. Bemelmans, G. J. Gelderblom, P. P. Jonker, L. De Witte, Socially assistive robots in elderly care: A systematic review into effects and effectiveness, Journal of the American Medical Directors Association, 2010, 13(2), 114-120.e1, DOI: https://doi. org/10.1016/j.jamda.2010.10.002

[28] J. E. Young, R. Hawkins, E. Sharlin, T. Igarashi, Toward acceptable domestic robots: Applying insights from social psychology, Journal of Social Robotics, 2009, 1(1), 95-108, https:// www.jst.go.jp/erato/igarashi/publications/001/SORO-1.pdf

[29] E. Broadbent, R. Stafford, B. MacDonald, Acceptance of healthcare robots for the older population: Review and future directions, Journal of Social Robotics, 2009, 1(4), 319-330, DOI: http: //dx.doi.org/10.1007/s12369-009-0030-6

[30] S. Lemaignan, M. Warnier, E. Akin Sisbot, A. Clodic, R. Alami, Artificial cognition for social human-robot interaction: An implementation, Artificial Intelligence, 2017, 247, 45-69, https: //doi.org/10.1016/j.artint.2016.07.002

[31] P. Rossi, The Birth of Modern Science, Blackwell Pub, 2001

[32] http://www.storiaolivetti.it/percorso.asp?idPercorso=649

[33] R. M. Cyert, The Impact of Technological Change on Employment and Economic Growth, David C. Mowery, 1988, 277

[34] International Federation of Robotics, World Robotics Report 2016, Statistics, Market Analysis, Forecast and Case Studies, https://ifr.org/ifr-press-releases/news/world-roboticsreport-2016

[35] https://www.istat.it/it/files/2017/03/Statistica-reportIndicatori-demografici_2016.pdf

[36] MIUR, Piano Nazionale Scuola Digitale, http://www.istruzione. it/scuola_digitale/index.shtml

[37] Scuola di Robotica, Progetto Ogeima Story: linguaggi umani, macchine, rappresentazioni, 2017-2018, https://www.scuoladirobotica.it/it/homesdr/1005/Progetto_ Ogeima_le_vostre_opinioni_sulla_collaborazione_tra_ umani_e_robot.html
[38] D. Silver et al., Mastering the game of Go with deep neural networks and tree search, Nature, 2016, 529, 484-489, https://storage.googleapis.com/deepmind-media/alphago/ AlphaGoNaturePaper.pdf

[39] C. Bartneck, T. Nomura, T. Kanda, T Suzuki, K. Kennsuke, Cultural differences in attitudes towards robots, In: Proceedings of the AISB Symposium on Robot Companions: Hard Problems and Open Challenges in Human-Robot Interaction, Hatfield, UK, 2005, 1-4, https://www.bartneck.de/publications/2005/ cultureNars/bartneckAISB2005.pdf

[40] N. Fairclough, Discourse and text: linguistic and intertextual analysis within discourse analysis, Discourse \& Society, 1992, 3(2), 193-217, https://doi.org/10.1177\% 2F0957926592003002004

[41] United Nations, General Assembly, Work of the Statistical Commission pertaining to the 2030, Agenda for Sustainable Development, Resolution adopted by the General Assembly, 10 July 2017, New York

[42] European Commission, The Digital Economy and Society Index (DESI), 2018, https://ec.europa.eu/digital-single-market/ en/desi

[43] M. Arntz, T. Gregory, U. Zierahn, The risk of automation for jobs in OECD countries: A comparative analysis, OECD Social, Employment and Migration Working Papers, No. 189, OECD Publishing, Paris, 2016, http://dx.doi.org/10.1787/5jlz9h56dvq7en

[44] McKinsey Global Institute, Jobs lost, Jobs gained: workforce transitions in a time of automation, 2017, https://www.mckinsey.com/ \{\}/media/McKinsey/Featured\% 20Insights/Future $\% 20$ of $\% 200$ rganizations/What $\% 20$ the $\%$ 20future\%20of\%20work\%20will\%20mean \%20for\%20jobs\% 20skills\%20and\%20wages/MGI-Jobs-Lost-Jobs-GainedReport-December-6-2017.ashx

[45] D. Acemoglu, P. Restrepo, Robots and Jobs: Evidence from US Labor Markets, NBER Working Paper No. 23285, 2017, DOI: 10.3386/w23285, http://www.sipotra.it/wpcontent/uploads/2017/04/Robots-and-Jobs-Evidence-fromUS-Labor-Markets.pdf 